\title{
Práticas etTnobiológicas para o desenvolvimento da COMPETÊNCIA INTERCULTURAL NA FORMAÇÃO DO PROFESSOR DE BIOLOGIA
}

\author{
Geilsa Costa Santos Baptista ${ }^{2 *}$, Geane Machado Araujo ${ }^{2}$
}

\author{
${ }^{1}$ Programa de Pós-Graduação em Ensino, Filosofia e História das Ciências, Universidade Estadual de Feira de Santana e Universidade Federal da Babia (UEFS-UFBA); \\ Grupo de Investigações em Etnobiologia e Ensino de Ciências (GIEEC-UEFS). \\ ${ }^{2}$ Universidade Estadual de Feira de Santana; Grupo de Investigações em Etnobiologia e Ensino de Ciências (GIEEC-UEFS). \\ *Autor para correspondência: geilsabaptista@gmail.com
}

Recebido em 01 de janeiro de 2018. Aceito em 03 de maio de 2018. Publicado em 20 de junho de 2018.

REsumo - Apresentamos e discutimos os resultados de uma pesquisa qualitativa baseada num estudo de caso envolvendo licenciandos em biologia de uma universidade pública do estado da Bahia, Brasil, que teve por objetivo identificar quais são as influências de experiências práticas envolvendo a etnobiologia aplicada ao ensino de ciências sobre a formação inicial do professor de biologia no que tange ao diálogo de saberes culturais. Após as suas vivências em atividades envolvendo a etnobiologia - de entrevistas semiestruturadas com feirantes, construção de recursos e sequências didáticas baseadas no diálogo intercultural a partir dos dados dessas entrevistas - solicitamos a construção de narrativas que revelassem as influências desta ciência nas suas formações como futuros professores. Análises sobre os dados obtidos permitiram a geração de categorias temáticas que nos permitiram a conclusão de que os licenciandos realizaram reflexões que lhes permitiram a construção de opiniões com significados que certamente influenciarão nas suas práticas pedagógicas para o diálogo intercultural.

Palavras-chave: Etnobiologla; Formaçäo inictal de professores; Pluralidade Cultural; Diálogos.

ETHNOBIOLOGY PRACTICES IN DEVELOPMENT OF INTERCULTURAL COMPETENCE FOR THE UNDERGRADUATE BIOLOGY TEACHER

\begin{abstract}
We present and discuss the results of a qualitative research based on a case study involving biology undergraduate students from a public university in the state of Bahia, Brazil. The objective was to identify the influences of practical experiences involving ethnobiology applied to science teaching regarding the initial training of biology teachers in relation to the dialogue of cultural knowledge. After experiences of the professors in activities involving ethnobiology - from semistructured interviews to construction of resources and didactic sequences based on intercultural dialogue - we requested the construction of narratives which would reveal the influences of this science on the process of formation as teachers. Analyzes of the data allowed the generation of thematic categories that allowed us to conclude that the undergraduates made reflections that allowed them to construct meaningful opinions that will certainly influence their pedagogical practices for intercultural dialogue.
\end{abstract}

Keywords: Ethnobiology; Initlal Teacher Training; Cultural plurality; Dialogues.

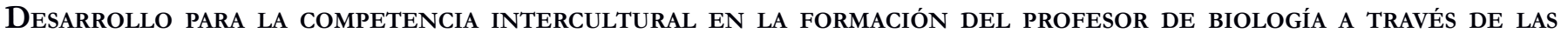
PRÁCTICAS DE LA ETNOBIOLOGÍA.

Resumen - Presentamos y discutimos los resultados de una investigación cualitativa basada en un estudio de caso 
envolviendo licenciandos en biología en una universidad pública del Estado de Bahia, Brasil. El objetivo del estudio fue identificar las influencias de experiencias prácticas envolviendo la etnobiología aplicada a la enseñanza de ciencias sobre la formación inicial del profesor de biología en lo referente al diálogo de saberes culturales. Después de sus experiencias en actividades etnobiológicas (entrevistas semiestructuradas con feirantes, construcción de recursos y secuencias didáticas basadas no diálogo intercultural a partir dos dados de estas entrevistas), solicitamos a los licenciados que hiciesen narrativas que revelasen las influencias de la Etnobiología en sus formaciones como futuros profesores. A través de los análisis de los datos obtenidos fue posible generar categorías temáticas que nos permitieron concluir que los licenciandos realizaron reflexiones que les permitieron la construcción de opiniones con significados que ciertamente influenciaran sus prácticas pedagógicas para el diálogo intercultural.

Palabras clave: Etnobiología; Formación iniclal de profesores; Pluralidad Cultural; Dlálogos.

\section{INTRODUÇÃO}

De acordo com Posey (1997), a etnobiologia é uma ciência que busca compreender os conhecimentos e as conceituações desenvolvidas por qualquer sociedade e suas culturas a respeito da biologia. Dito em outras palavras, a etnobiologia é o estudo das relações entre os seres humanos e os demais seres vivos tendo as culturas como mediadoras desse processo.

Os estudos etnobiológicos estão voltados para vários campos, como, por exemplo, a etnobotânica, a etnozoologia, a etnofarmacologia, etnomicologia, entre outros, podendo ter duas diferentes abordagens: utilitarista e intelectualista (Berlin 1992). A abordagem utilitarista questiona como e de que modo as sociedades humanas utilizam a natureza, já a abordagem intelectualista, procura saber como e de que modo as sociedades humanas veem ou concebem a natureza. Como exemplo de estudo utilitarista é possível citar o de Costa-Neto (2011), que discute o uso de animais como recursos medicinais no Estado da Bahia, nordeste brasileiro. Já de estudo intelectualista tem-se o de Prado (2012), voltado para os conhecimentos de quilombolas do Vale do Ribeira (SP, Brasil) sobre dieta e uso de habitats por grandes mamíferos silvestres.

As pesquisas etnobiológicas estão baseadas nos estudos etnocientíficos e nas técnicas etnográficas. Os estudos etnocientíficos, segundo Toledo (1990), se dedicam à investigação da soma total dos conhecimentos que um determinado grupo cultural tem sobre o universo social e natural, bem como sobre si mesmo. Assim, os procedimentos de pesquisa da etnobiologia podem incluir técnicas como observações, entrevistas, questionários, fotografias, filmagens, desenhos, entre outras.

Seja qual for o procedimento adotado pelo pesquisador, os estudos etnobiológicos podem ter várias aplicabilidades. Podem contribuir para soluções de problemas ecológicos em vastas regiões do mundo - como, por exemplo, a destruição de florestas em áreas tropicais e a extinção em massa de origem antrópica de espécies animais e vegetais - por revelarem conhecimentos milenares que ainda permitem a conservação do equilíbrio ecológico em diversas regiões. Mas não apenas isto, também podem contribuir para preservação de saberes locais, os quais constituem um patrimônio da humanidade (Posey 1997; Kuhnlein 2014).

$\mathrm{Na}$ área de ensino de ciências, a etnobiologia constitui importante caminho para que os professores tenham uma formação culturalmente sensível, isto é, que investiga, compreende e considera os conhecimentos culturais dos estudantes para o envolvimento no diálogo cultural com a ciência (Baptista 2007; 2012). O diálogo na educação escolar constitui um encontro entre seres humanos, no qual ocorre o refletir com criticidade e o agir dos sujeitos (Freire 1987). No ensino de ciências, dialogar consiste das relações de comunicação que são 
estabelecidas entre o professor e os estudantes, e entre os estudantes, sobre um determinado tema que é foco do ensino e aprendizagem. Nessas relações, os diversos saberes que são culturais, tanto da ciência ensinada quanto dos meios sociais dos estudantes, são apresentados e considerados segundo seus próprios critérios de origem e de aplicabilidade (Lopes 1999). No diálogo não deve ocorrer tentativas de hierarquizações e substituições das ideias dos estudantes por ideias científicas, mas, sim, negociação de significados culturais e de contextos de aplicabilidade de cada um dos conhecimentos envolvidos. O propósito deve ser sempre a ampliação das visões de natureza.

Para Baptista (2007), que realizou uma pesquisa sobre as contribuições da etnobiologia para a formação continuada de professores de ciências, os professores poderão utilizar a etnobiologia para investigação e compreensão dos saberes culturais dos estudantes ligados à natureza por duas vias: 1) por meios da utilização dos seus procedimentos metodológicos em salas de aula ou em campo, nas comunidades de onde os estudantes são provenientes (p. ex. as técnicas etnográficas: entrevistas, observações, realização de desenhos, filmagens etc.) ou 2) através das suas publicações contendo saberes etnobiológicos de uma determinada comunidade. Dessa investigação, poderão elaborar e aplicar recursos e sequências didáticas baseadas no diálogo cultural entre os conhecimentos científicos ensinados e os conhecimentos culturais dos estudantes, podendo estabelecer entre eles inúmeras relações, sejam elas de semelhanças e/ou de diferenças no que tange às suas epistemologias (Baptista 2007).

Visto que a etnobiologia pode contribuir para o ensino e formação de professores de ciências seja através das suas publicações e/ou através dos seus procedimentos de pesquisa em campo (Baptista 2007) é que apresentamos os resultados de um estudo realizado com estudantes da Licenciatura em Biologia da Universidade Estadual de Feira de Santana (UEFS), Bahia, Brasil que teve por objetivo identificar quais as influências de experiências práticas envolvendo a etnobiologia aplicada ao ensino de ciências sobre a formação inicial do professor de biologia no que tange à sua competência para a realização do diálogo de saberes culturais. A seguinte questão problema deu origem ao referido estudo: - Na opinião do licenciando em biologia, a etnobiologia aplicada ao ensino de ciências pode contribuir para a sua formação inicial que seja sensivel à diversidade cultural? Partimos da premissa de que é imperativo que as instituições de ensino superior forneçam aos futuros professores oportunidades para reflexões e desenvolvimento de habilidades que contribuirão para que operem eficientemente no ensino em contextos culturalmente diferentes (Ochoa et al. 2016).

Esperamos que os dados aqui apresentados possam servir como motivação para outros estudos envolvendo a etnobiologia e formação de professores de ciências para lidar com a diversidade cultural através de diálogos, não apenas no contexto educacional brasileiro, mas, também, de outros países, que tenham nas suas realidades de escolas e salas de aula estudantes provenientes de diferentes culturas, sendo a própria ciência ensinada uma entre elas.

\section{Metodologia}

Abordagem da pesquisa e sujeitos participantes

Esta pesquisa, de abordagem qualitativa baseada no estudo de caso (Martins 2004; André 2013), foi realizada no ano de 2016, durante o semestre 2016.1 da Universidade Estadual de Feira de Santana (UEFS), município 
localizado a $116 \mathrm{~km}$ da cidade de Salvador, capital do estado da Bahia.

Estiveram envolvidos 18 licenciandos, dos gêneros masculino e feminino, cujas idades variaram entre 17 e 29 anos e que frequentavam as atividades do componente curricular Pluralidade Cultural e Inclusão Escolar (EDU 354), do curso de Licenciatura em Ciências Biológicas da UEFS. Dados obtidos junto ao site do Colegiado (http://www1.uefs.br/portal/colegiados/ciencias-biologicas; 2017), indicam que este curso tem por objetivo formar professores para atuarem na educação Básica do Brasil, no ensino de ciências naturais (Nivel Fundamental, dos 11 aos 14 anos) e de biologia (Nível Médio, dos 15 aos 17 anos de idade).

Edu 354 é ofertado no terceiro semestre do curso e possui carga horária total de 75 horas, sendo 5 horas por semana. A carga horária total destinada às atividades do estudo ora relatado foi de 40 horas. A sua ementa prevê como abordagem principal: A escola como espaço sociocultural; refletir sobre a diversidade dos sujeitos, a produção do conhecimento biológico e as questões das diferenças de gênero, de corpo, de sexualidade; a relação entre ciência e outras formas de conhecimento no âmbito da educação; cruzamento de fronteiras culturais na aprendizagem de ciências e biologia em diferentes contextos educativos. No que tange à diversidade cultural, é importante informar que esta ementa está de acordo com a legislação pública da educação no Brasil (Brasil 1996; 1997; 2003a; 2008).

\section{Coleta de dados}

Inicialmente, na sala de aula da UEFS, visando permitir aos licenciandos vivenciar experiências das práticas da etnobiologia voltadas ao ensino de ciências, foi realizada pela orientadora do componente (primeira autora deste artigo) uma exposição teórica sobre a etnobiologia, seus conceitos, histórico, abordagens, aplicabilidades, procedimentos metodológicos de pesquisa, ramificações e exemplos. Sobre as ramificações, uma ênfase foi dada ao ensino de ciências, dado o objetivo mais amplo da parte prática de EDU 354. A referida exposição buscou a participação dos sujeitos, no sentido de permitir-lhes as suas falas no que tange aos seus conhecimentos prévios acerca da etnobiologia. Como forma de ampliar os seus saberes a respeito do assunto, indicamos as seguintes bibliografias, as quais foram lidas e discutidas pelos licenciandos em sala de aula sob a forma de seminários (Marques 2002; Baptista 2007; 2015).

Após a exposição teórica e discussão dos textos, os licenciandos foram divididos em dois grupos principais, a saber: 1- Etnobotânica e 2. Etnozoologia. Dentro de cada grupo, eles foram subdivididos por trios. Cada trio formou parte de uma aplicabilidade dentro desses dois grandes grupos, a saber: Alimentício, Medicinal e Artesanal.

Cada trio, por sua vez, foi convidado a escolha de uma temática de ensino, que poderia ser para ciências naturais ou biologia e, com base nisto, elaborar um protocolo com questionamentos para entrevistas semiestruturadas com feirantes do município de Feira de Santana. O objetivo dessas entrevistas foi identificar os conhecimentos locais que pudessem estabelecer relações de semelhanças e/ou de diferenças com os saberes científicos que são trabalhados nas escolas, em Ciências (Nível Fundamental) ou Biologia (Nível Médio) (Baptista 2007).

A fim de gerar a construção desse protocolo, foram pontuadas as seguintes questões norteadoras: O que conhecem e praticam os feirantes de Feira de Santana sobre as plantas ou animais que são por eles comercializados? - Que relações de semelhanças e de diferenças poderiam ser estabelecidas entre esses saberes com os conteúdos que são trabalhados nas salas de aulas de ciências e/ou de biologia? Estas serviram de base 
para reflexões entre os licenciandos que compuseram cada trio.

Dado o curto espaço deste trabalho, e somente a fim de esclarecimento ao leitor, pois que não é objetivo deste artigo apresentar os resultados das entrevistas realizadas pelos estudantes com os feirantes, apresentaremos apenas uma de cada conjunto de questões que compuseram os protocolos dos seis trios que participaram do estudo, a saber: Trio 1: Etnobotânica-Alimentar: - Por que as verduras que são vendidas por vocês são regadas com água?; Trio 2: Etnozoologia-Alimentar: - Qual o nome das partes do animal que você vende?; Trio 3: Etnobotânica-Medicinal: - Quais plantas medicinais são vendidas na sua barraca e para que servem?; 4 Etnozoologia-Medicinal: - Qual nome do animal ou animais que você usa e recomenda como remédio e para quais enfermidades?; Trio 5: Etnobotânica Artesanal: Qual tipo de planta que você mais utiliza nos seus produtos artesanais e de que forma você consegue obter essas plantas?; Trio 6: Etnozoologia-Artesanal: - Qual o significado tem as corujas que você vende?

Após a construção do protocolo com questionamentos, os licenciandos, em conjunto com a orientadora e a monitora do componente curricular (segunda autora deste trabalho), indicaram o Centro de Abastecimento de Feira de Santana (CAFS, figura 1) para realização das entrevistas com os feirantes que ali trabalham como sendo o melhor espaço para a realização do estudo.

Figura 1 - Vistas parciais do Centro de Abastecimento de Feira de Santana. Fonte: Fotografias realizadas pela segunda autora durante as intervenções (2017).
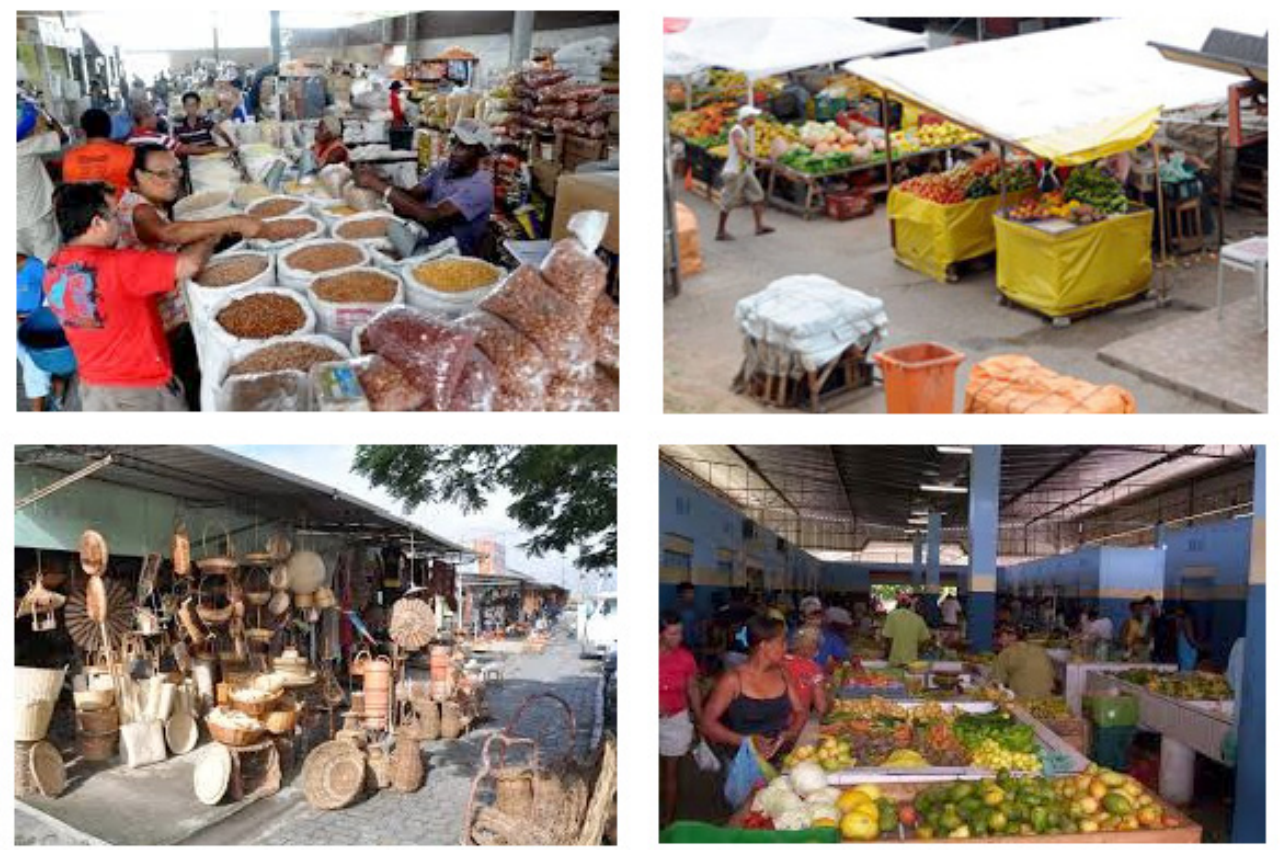

Cumpre informar que o CAFS está localizado na cidade de Feira de Santana, a $116 \mathrm{Km}$ da cidade do Salvador, capital da Bahia, região Semiárida do Nordeste do Brasil e que este espaço foi escolhido por melhor representar a cultura local e regional. A região onde nossa pesquisa foi desenvolvida, cujo principal ecossistema é a Caatinga, é marcada por difíceis condições socioeconômicas e ambientais. O clima é semiárido, seco e quente, com temperatura média anual entre $25^{\circ} \mathrm{C}$ e $35^{\circ} \mathrm{C}$. Ocorre baixa pluviosidade, o que dificulta o desenvolvimento da agricultura e pecuária, principais fontes de renda e sobrevivência da população rural, gerando desemprego e pobreza na região. Apesar desta realidade, o povo nordestino ainda mantém as suas tradições culturais populares, desde a colonização, influenciadas pela miscigenação étnica e cultural entre indígenas, africanos e portugueses, 
além de outras que foram se formando ao longo do processo histórico do Brasil. São tradições fortemente representadas por diversas vias, como narrativas orais, literaturas, canções, danças, festejos, vestuários, culinárias, artefatos, religiões etc., podendo envolver elementos naturais, não naturais e do imaginário humano.

Segundo informações obtidas junto ao próprio CAFS, neste espaço são comercializados produtos com diversas finalidades, como por exemplos, amuletos confeccionados com animais como o caburé (Glaucidium brasilianum); remédios com animais e plantas, como a jibóia (Boa constrictor) e a umburana (Amburana cearensis) respectivamente. Também são vendidos artigos feitos de couro bovino e plantas, por exemplo o sisal (Agave sisalana), como bolsas, malas, sapatos, chapéus, tapetes, etc., além de alimentos como frutas, verduras, aves e mariscos, entre outros. Assim, a escolha do CAFS se deu principalmente pelo fato de este envolver trabalhadores que atuam na venda de produtos que incluem aspectos culturais típicos da região. Estes trabalhadores, certamente, podem ser pais ou estudantes da escola Básica, nos níveis Fundamental ou Médio. Além disto, escolhemos o CAFS devido a este ser um centro comercial localizado na parte central do município de Feira de Santana, o que facilitaria o acesso por parte dos licenciandos.

Tendo os licenciandos concordado com a escolha do CAFS para visita, foram orientados à realização de duas visitas a este centro, cada uma perfazendo um total de 4 horas, visando seguir alguns dos procedimentos das pesquisas etnobiológicas. O objetivo do primeiro encontro foi sondagem prévia e primeiros contatos com os informantes locais, ou estabelecimento de um Rapport, isto é, vínculos de confiança com os informantes do local. Já a segunda visita objetivou a realização das entrevistas semiestruturadas. Os licenciandos deveriam questionar os feirantes com base nas suas perguntas previamente elaboradas e registrar os dados por duas vias: ou diário de campo ou gravação, que poderia ser filmagem ou áudio, a depender da receptividade de cada informante e assinatura de um termo de consentimento de participação na pesquisa (Brasil 2003b). Neste termo, os feirantes foram informados que poderiam utilizar câmera de filmar, celular ou gravador digital e que eles poderiam aceitar ou recusar as suas participações. Eles foram informados, ainda, que os dados coletados nas entrevistas serviriam para elaboração e recursos e sequências didáticas pelos licenciandos em biologia da UEFS como forma de contribuição para as suas formações e ensino de ciências e biologia que respeita e considera a diversidade de saberes culturais.

Ao término das suas atividades no CAFS, os licenciandos retornaram para suas residências sendo orientados a transcreverem as suas entrevistas e leva-las para aula seguinte, que aconteceu uma semana após. Para esta aula, a orientadora solicitou-lhes que levassem, além das entrevistas transcritas, livros didáticos de ciências naturais, de biologia e textos científicos da etnobiologia que contivessem as temáticas de ensino por eles escolhidas.

De volta a sala de aula na UEFS após uma semana, os licenciandos buscaram estabelecer relações entre os saberes locais dos feirantes e os saberes científicos que são trabalhados como conteúdos de ensino nas escolas. Para isto, eles realizaram consultas aos livros didáticos de ciências naturais, de biologia e também a bibliografia científica especializada na área da etnobiologia que lhes foram solicitadas anteriormente. Nesse momento, foram abertos diálogos com a orientadora visando facilitar o estabelecimento dessas relações.

Após a busca de relações entre os saberes culturais dos estudantes e os saberes científicos, os licenciandos, ainda dispostos em trio e na sala de aula da UEFS, elaboraram um recurso e sequência didática para o diálogo intercultural referente à etnozoologia e à etnobotância. Por fim, esses recursos e sequências didáticas foram apresentados por cada trio aos demais na sala de aula da UEFS. Nesses momentos, houve questionamentos, problematizações, sugestões, enfim compartilhamentos de ideias e saberes pedagógicos voltados ao ensino de 
ciências naturais e biologia que seja sensível à diversidade cultural por meio de diálogos. As observações e reflexões realizadas pelas autoras durante esses momentos foram anotadas num diário de campo. O objetivo foi somar dados para a compreensão de como uma atividade envolvendo a etnobiologia poderia contribuir para a formação inicial do professor de biologia.

Com o intuído de levantar dados para a escrita deste artigo, os licenciandos - após as apresentações dos seus recursos e sequências didáticas - foram convidados a escrita de uma narrativa a partir do seguinte questionamento: - Como a atividade envolvendo a etnobiologia, de investigação de saberes culturais, produção de um recurso e sequência didática, contribuiu para a tua formação inicial no que tange à diversidade cultural nas salas de aula de ciências e de biologia? Entendemos por narrativa uma exposição de fatos, acontecimentos ou uma história. Esperávamos narrações por parte dos licenciandos acerca das suas vivências com os feirantes do CAFS, construções dos recursos e sequências didáticas e, de forma associada, explicações sobre como a etnobiologia teria contribuído para as suas formações como futuros professores de biologia. Cumpre informar que com o intuito de garantir a privacidade dos sujeitos, solicitamos que os licenciandos não se identificassem nas suas respostas.

Os dados foram analisados segundo Bardin (1977). De acordo com esta autora, o texto é um meio de expressão do sujeito. $\mathrm{Na}$ análise do conteúdo de um texto, o pesquisador vai buscar categorizar as unidades desse texto (palavras ou frases) que se repetem, inferindo uma expressão que as representem com frequência. Assim, na análise por categorias temáticas será possível encontrar significações agrupadas naquilo que têm em comum. No estudo ora apresentado, das análises sobre as narrativas buscou-se eleger categorias temáticas contendo as significações atribuídas pelos licenciandos às suas experiências vividas durante a parte prática de EDU 354, que envolveu a etnobiologia aplicada ao ensino de ciências e biologia. Sobre essas análises, procederam-se discussões com apoio da literatura específica das áreas de educação e de ensino de ciências bem como por elas utilizada.

\section{Resultados E Discussão}

Dos vinte licenciandos matriculados no componente EDU 354, houve desistência de dois, por razões não conhecidas. Sendo assim dezoito licenciandos participaram do nosso estudo. No lugar de escreverem narrativas, os licenciandos apresentaram respostas diretas ao questionamento que lhe foi feito. Isto pode ter acontecido pela não compreensão do significado de uma narrativa das suas partes ou, então, tenha sido preferencial para eles a não opção por narrar as suas experiências durante as atividades. Das análises das respostas dadas pelos participantes, foi possível a criação de quatro categorias temáticas. A seguir cada uma dessas categorias será pontuada com trechos das respostas de alguns licenciandos como exemplo seguidos de discussão. Com intuito de facilitar a compreensão dos resultados, importa dizer que foi gerado um código de identificação para cada um dos participantes, a saber: L1 para o primeiro licenciando, L2, para o segundo licenciando, e assim sucessivamente. A ordem seguiu a sequência da entrega.

\section{Categoria 1: Percepção da existência de uma diversidade de saberes culturais no âmbito escolar}

Quando os professores percebem os espaços das escolas como sendo multiculturais, eles podem adaptar as suas propostas educativas às realidades dos sujeitos que frequentam esses espaços, podendo compartilhar saberes e promover a coexistência pacífica entre as diferentes culturas (Gomes 2003). Os licenciandos em 
biologia, após suas participações nas atividades envolvendo os saberes dos feirantes do CAFS, demonstraram perceber a existência dessa multiplicidade de culturas nas salas de aula, como é possível observar nas suas falas abaixo:

Esta atividade ajudou no desenvolvimento de uma concepção mais abrangente acerca da biologia e de como os conbecimentos populares estarão sempre presente dentro do ambiente escolar. Trabalhar diretamente com os conbecimentos dos feirantes melhora o entendimento de muitos aspectos que formam a nossa cultura. Pensar e realizar um recurso e sequência didática ajuda no desenvolvimento de várias competências de nós enquanto professores, pois devemos organizar os dados coletados e fazer planos e aula (L8).

Contribuiu com a aprendizagem de novos conteńdos. Com a observação dos saberes culturais de alguns cidadãos conclui que cada um deles possui cultura, costumes e saberes diferentes, do mesmo modo ao relacionar nas salas de aulas de biologia nos deparamos com alunos que possuem diversas culturas, que vem de suas casas com conbecimentos prévios diferentes e nós como professores devemos utilizar isso ao nosso favor e nos adaptamos (L11).

O fato de os licenciandos reconhecerem as salas de aula como espaços multiculturais constitui um excelente indicativo de que a atividade envolvendo aspectos teóricos e metodológicos da etnobiologia contribuiu para reflexões que poderão intervir nas suas futuras práticas pedagógicas. Especialmente para que investiguem os conhecimentos prévios dos estudantes acerca dos fenômenos naturais e a partir deles elaborem e apliquem estratégias de ensino e aprendizagem voltadas ao diálogo intercultural. Isto certamente contribuirá para motivação das participações dos estudantes, uma vez que serão geradas oportunidades para exposição das suas falas e saberes que são inerentes aos seus cotidianos socioculturais. Todavia, acredita-se que para que isto ocorra é preciso que estas estratégias sejam ativas, não permitindo a passividade dos sujeitos como acontece com frequência durante as atividades direcionadas à simples transmissão de conteúdos científicos (pedagogia transmissiva). É preciso utilizar estratégias que envolvam problematizações e busca de soluções, como, por exemplos, os jogos, as dramatizações, a exibição de filmes e manuseio de recursos tecnológicos, como computadores e celulares. O intuito deverá ser sempre incluir participações ativas, acautelando-se do cientificismo, que tem a Ciência Ocidental como cultura dominante, a única a ser representada nas salas de aula, por possuir as melhores respostas para os questionamentos do homem. Além da ciência ocidental moderna, existem outros modos de conhecer, que podem e devem ser respeitados, segundo seus próprios critérios de origem e de aplicabilidade.

\section{Categoria 2: Respeito pela heterogeneidade de saberes dos estudantes e importância de relacioná-los aos saberes científicos}

De acordo com Lee (2001), à medida que a população estudantil das nações se torna mais diversificada culturalmente, os educadores estão cada vez mais conscientes da necessidade de ensinar a todos os estudantes a ciência ocidental - tal como é tradicionalmente praticado na comunidade científica e ensinado nas escolas para que possam participar ativamente das sociedades científica e tecnologicamente influenciadas e, ao mesmo tempo, respeitar as diversas línguas e culturas que esses sujeitos trazem consigo para a sala de aula de ciências.

No que tange ao respeito pela diversidade de saberes culturais ligados à natureza, a etnobiologia certamente pode auxiliar os professores, porque esta ciência tem entre os seus objetivos investigar, compreender e elucidar quais são os conhecimentos que diferentes culturas possuem acerca do mundo natural (Baptista and El-Hani 2009). Este objetivo foi compreendido pelos licenciandos em Biologia ao realizarem atividades didáticas envolvendo a etnobiologia. As seguintes respostas comprovam esta afirmativa: L1: “[...] a etnobiologia contribuin para entender os saberes culturais e respeitá-los”; L9: “... entendi que meu papel em sala de aula é reconbecer, respeitar e compreender 
a cultura dos indivíduos e fazer com que os outros no espaço façam o mesmo [...]".

Os licenciandos também apontaram que esta ciência contribui para a percepção de que os saberes dos estudantes podem ser relacionados aos saberes científicos nos momentos de ensino e isto contribuirá para a ampliação das suas visões de mundo, como é possível observar nas seguintes respostas: L12: '[...] compreendi que devemos respeitar as ideias do senso comum, os saberes trazidos pelos alunos. Meu papel... é apenas informar aos alunos uma nova forma de olhar os processos naturais, sem criticar, desprezar ou desconsiderar os saberes dos alunos”; L3: "[...] contribuiu para perceber e entender que cada individuo carrega com ele um saber cultural, o qual não deverá ser ignorado ou considerado como errado, e sim relacionado ao saber cientifico".

Para os licenciandos, o estabelecimento de relações entre os saberes culturais dos estudantes e os saberes científicos trabalhados na escola contribuem para que o professor consiga trabalhar os conhecimentos científicos minimizando conflitos que porventura possam ocorrer nas salas de aula: L4: "[...] contribuiu de uma forma com que eu possa relacionar os conbecimentos populares e culturais com os conbecimentos cientificos podendo também conciliá-los para saber aplicar certos assuntos em sala de aula sem causar alguns conflitos [...]"; L15: "[...] associar os conteúdos das ciências biológicas com os conhecimentos trazidos pelos alunos culturalmente, de modo que o aluno amplie sua visão de mundo, e possa compreender os assuntos sem ocasionar conflitos com os seus saberes culturais". Entendemos essa possibilidade de conflito apontada pelos licenciandos como importante para as suas formações no que tange ao ensino de ciências baseado no diálogo entre saberes culturais. Partimos da premissa de que o diálogo no ensino de ciências não está interessado em debates e nem hierarquizações, ou seja, na contestação, disputa por superioridade entre ideias culturais que possam ser conflitantes, mas, sim, nas exposições de ideias como meio de ampliar as ideias dos estudantes com ideias científicas. Como bem argumenta Bohm (2005), o propósito do diálogo não é o julgamento de verdades, mas a exploração e compreensão do pensamento humano. Diálogos no ensino de ciências são relações de comunicação que visam o compartilhamento de significados culturais entre professores e estudantes e entre estudantes sobre um determinado tema que é objeto de ensino e aprendizagem. Neste sentido, é importante destacar, o professor não deve perder de vista o objetivo de que os estudantes desenvolvam uma compreensão adequada dos conhecimentos ensinados, que são científicos. Dialogar no ensino de ciência significa apresentar um conteúdo científico e abrir espaços para que os estudantes o relacionem ao que já sabem, seja em termos de semelhanças, seja em termos de diferenças epistemológicas.

\section{Categoria 3: Aproximação das realidades dos estudantes e aprendiragem cientifica}

Conforme já dito, as relações dialógicas no ensino de ciências precisam estar interessadas na exposição das ideias por parte dos interlocutores. Isto, por sua vez, envolve diferentes tipos de linguagens, incluindo a científica e a não científica. Esta premissa foi apontada nas respostas dos licenciandos, servindo como exemplo o seguinte trecho L7: "O diálogo envolve a linguagem cientifica de forma interativa com os estudantes. Assim, contribui para a aprendizagem... de forma significativa e a formação dos professores sensiveis ao conbecimento popular". Como é possível notar, o licenciando reconhece que a linguagem científica está presente no diálogo que possa ocorrer no ensino de ciências e, além disto, enfatiza que esta linguagem interage com os estudantes.

Assim, entendemos como necessário que os professores além de se preocuparem com a linguagem científica que estão representando, deem atenção às linguagens utilizadas pelos estudantes (narrativas, desenhos, imagens, canções, gestos, expressões faciais etc.), pois através destas poderão ser revelados conhecimentos e sentimentos 
que serão úteis na comunicação e construção de significados científicos nas salas de aula. Porque a linguagem utilizada pelo estudante pode explicitar saberes inerentes à sua realidade.

É interessante dizer que entre as respostas dos licenciandos encontramos afirmativas de que a linguagem científica difere da linguagem dos estudantes: L10: "O primeiro aprendizado foi juntar o conbecimento popular com o conhecimento cientifico, embora a linguagem popular seja diferente da cientifica isso não quer dizer que seja errado...”. Esta afirmativa está de acordo com a literatura da área de ensino de ciências que trata sobre interações discursivas nas salas de aula de ciências. Segundo Mortimer et al. (1998), a linguagem trazida pelos estudantes para as salas de aula difere da linguagem científica. Sendo assim, é preciso atentar para o modo como os estudantes expressam os seus saberes e, ao mesmo tempo, auxiliá-los ao uso da linguagem da ciência, porque, como bem indica Mortimer et al. (1998), aprender ciências é, também, aprender a se expressar na linguagem científica.

A transcrição acima também revela o entendimento de que a linguagem dos estudantes não pode ser considerada errada apenas por ser diferente da linguagem científica. Um dado discurso, por exemplo, como sendo constituinte da linguagem, só pode ser considerado correto tendo em apreço o contexto em que as expressões forem usadas (Leite et al. 2001). As palavras de um discurso podem ter significados diferentes em contextos diversos. Assim, durante um diálogo, o professor pode considerar uma determinada linguagem utilizada pelo estudante como sendo inconsistente com a ciência, mas não como errada e inferior. Uma linguagem tem significante e significado e exerce a função suprema de representação da visão de mundo do sujeito e dos seus saberes. Estes, por sua vez, possuem seus próprios contextos culturais de origem e de aplicabilidade.

\section{Categoria 4: Aumento dos saberes docente}

Para os licenciandos, a experiência por eles vivenciada durante as atividades de EDU 354 L14: "Contribuiu... para o entendimento maior dos saberes culturais... que são de fundamental importância para nossa formação"; "... permitindo que os alunos possam notar que existe uma pluralidade cultural fora e dentro da escola". Certamente, a etnobiologia pode coadjuvar a formação do professor de ciência, porque contribui para o ensino de ciências fornecendo dados sobre como os estudantes - que são membros de diferentes sociedades e suas culturas - conhecem e se relacionam com a natureza ao seu redor. Isto contribuirá para o direcionamento de aulas para que sejam dialógicas, porque os saberes culturais poderão ser incluídos e respeitados segundo as suas origens e contextos de aplicabilidade. Os professores e os estudantes poderão, através do diálogo, estabelecer inúmeras relações entre os saberes científicos e os saberes dos estudantes, sem que ocorram hierarquizações (Baptista 2007).

\section{CONSIDERAÇÕES FINAIS}

Os resultados indicam que para os licenciandos em Biologia da UEFS a etnobiologia contribuiu para as suas formações nos seguintes aspectos: Percepção da existência de uma diversidade de saberes culturais no âmbito escolar; Respeito pela heterogeneidade de saberes dos estudantes e importância de relacioná-los aos saberes científicos; Aproximação das realidades dos estudantes e aprendizagem científica; Aumento dos saberes docente.

A partir das nossas discussões, concluímos que estes achados possuem grande relevância para a formação inicial do professor de ciências que seja culturalmente sensível, porque evidenciam que os licenciandos envolvidos 
no nosso estudo realizaram reflexões que thes permitiram a construção de opiniões com significações que certamente influenciarão nas suas futuras práticas pedagógicas para que realizem o diálogo cultural da ciência com os saberes dos estudantes. Também evidenciam que quando são oferecidas oportunidades de aprendizagem da docência com estratégias e ambientes adequados - como neste caso que utilizamos estratégias da etnobiologia para coleta de dados no espaço sociocultural de feirantes - a competência para o ensino intercultural poderá ser desenvolvida de maneira significativa.

Apesar destes achados, nosso estudo teve algumas lacunas e sugerimos alternativas com relação ao número de participantes, tempo de envolvimento com os informantes local (feirantes do CAFS), estratégias das pesquisas etnobiológicas que foram utilizadas para envolvimento dos licenciandos com a etnobiologia e aplicação dos recursos e sequências didáticas produzidas com estudantes na escola. No que tange ao número de participantes e tempo envolvido na pesquisa, julgamos ser necessária a realização de novos estudos que envolvam uma amostra maior num tempo mais prolongado que um semestre letivo universitário de aulas, a fim de elucidar de forma mais ampla, detalhada e comparativa sobre como a etnobiologia pode contribuir para formação inicial de professores de biologia a partir das opiniões destes sujeitos, além das que foram aqui reveladas.

Com relação às estratégias da etnobiologia que foram utilizadas com os licenciados participantes do nosso estudo, avaliamos como necessária a utilização de outras técnicas, além da entrevista semiestruturada e rapport: - Observação direta e participante, que poderá contribuir para elucidação das realidades cotidianas dos informantes e suas atividades bem como para a interação pesquisador/pesquisado; - Desenhos esquemáticos, que como um tipo de linguagem não verbal, poderão abrir espaços para representação de saberes por aqueles informantes que sentirem dificuldades de expressão oral; - Fotografias, que ajudarão nas análises das imagens construídas pelos participantes da pesquisa sobre um determinado elemento ou fenômeno da natureza.

Por último, reconhecemos que os licenciandos poderiam ter aplicado os recursos e sequências didáticas que eles produziram nas salas de aula das escolas da região, como forma de vivenciar as primeiras experiências de ensino baseado no diálogo intercultural. Justificamos esta ausência pela falta de tempo prolongado e acessibilidade aos planejamentos dos professores de ciências e biologia que já atuam nessas escolas. Pretendemos, como forma de minimização desta lacuna, e também ampliação dos nossos estudos, a análise desses recursos e sequências didáticas por outro grupo de licenciandos que venham a cursar EDU 354. A partir dessas análises, esses licenciandos poderão fazer modificações e/ou inserções de novos conteúdos, objetivos e estratégias de ensino, entre outros aspectos, que visem o diálogo intercultural.

Apesar das lacunas encontradas, afirmamos que nosso estudo forneceu um primeiro mapeamento sobre as possíveis categorias que podem agrupar as contribuições da etnobiologia para a formação docente inicial culturalmente sensível. Entendemos que a partir deste estudo outros poderão ser realizados para ampliar a geração de dados que poderão contribuir para melhorar os currículos de formação do professor de biologia que vise o respeito e consideração da diversidade cultural. Partiremos sempre da premissa de que é imprescindível que os cursos de formação de professores gerem oportunidades de experiências práticas in loco, para além da teoria trabalhada.

\section{Agradecimentos E apoios}

Ao Departamento de Educação (UEFS), Brasil; Grupo de Investigações em Etnobiologia e Ensino de 
Ciências (GIEEC-UEFS) e aos licenciandos do curso de Biologia do Departamento de Biologia da UEFS.

\section{REFERÊNCIAS}

André M. 2013. O que é um estudo de caso qualitativo em educação? Revista da FAEEBA: Educação e Contemporaneidade, 22(40): 95-103.

Baptista G C S. 2007. A Contribuição da etnobiologia para o ensino e a aprendizagem de Ciências: estudo de caso em uma escola pública do Estado da Bahia. Dissertação de mestrado apresentada ao Programa de Pós-graduação em Ensino, Filosofia e História das Ciências, Salvador, Universidade Federal da Bahia - Universidade Estadual de Feira de Santana.

Baptista G C S 2012. A etnobiologia e sua importância para a formação do professor de ciências sensível à diversidade cultural: indícios de mudanças das concepções de professoras de biologia do estado da Bahia. Tese de doutorado em Ensino, Filosofia e História das Ciências, Salvador, Universidade Federal da Bahia (UFBA) - Universidade Estadual de Feira de Santana (UEFS).

Baptista G C 2015. Um enfoque etnobiológico na formação do professor de ciências sensível à diversidade cultural: estudo de caso. Ciência \& Educação, Bauru, 21(3): 585-603.

Baptista G C, El-Hani C N 2009. The contribution of ethnobiology to the construction of a dialogue between ways of knowing: A case study in a Brazilian public high school. Science \& Education, 18(3-4): 503-520.

Bardin L. 1977. Análise de Conteúdo, Lisboa: Edições 70, 229 p.

Berlin B. 1992. Ethnobiological classification: principles of categorization plants and animals in traditional societies, New Jersey: Princeton University Press, 336 p.

Bohm D. 2005. Diálogo: comunicação e redes de convivência, São Paulo: Palas Athena, 184 p.

BRASIL. Lei de Diretrizes e Bases da Educação Nacional (LDBEN). Brasília: Diário Oficial, ANO CXXXIV, Número 248, 1996.

BRASIL. Ministério da Educação. Secretaria de Educação Fundamental. Parâmetros curriculares nacionais: pluralidade cultural, orientação sexual. Brasilia, DF: MEC/SEF, 1997.

Brasil. Presidência da República. Lei n. ${ }^{10.639}$, Diário Oficial da União, Brasília, DF, 10 janeiro de 2003a, p. 1. Brasil. Ministério da Saúde. Conselho Nacional de Saúde. Comissão Nacional de Ética em Pesquisa. Normas para pesquisa envolvendo seres humanos. $2^{a}$ Edição, Brasília, $2003 \mathrm{~b}$.

Brasil. Presidência da República. Lei no 11.645, Diário Oficial da União, Brasília, DF, 11 de março de 2008, p. 1. Costa-Neto E M. 2011. A zooterapia popular no Estado da Bahia: registro de novas espécies animais utilizadas como recursos medicinais. Ciência \& Saúde Coletiva, 16(1): 1639-165. 
Freire, P. 1987. Pedagogia do Oprimido, 17ª ed. Rio de Janeiro, Paz e Terra, 184 p.

Gomes N L. 2003. Educação e Diversidade Étnicocultural. In: Ramos M N, Adão J M, Barros G M N (coordenadores). Diversidade na Educação: reflexões e experiências, Brasília: Secretaria de Educação Média e Tecnológica/MEC, p. 67-76.

Kuhnlein, H V. 2014. How ethnobiology can contribute to food security. Journal of Ethnobiology, 34(1): $12-27$.

Lee O. 2001. Culture and language in science education: what do we know and what do we need to know? Journal of Research in Science Teaching. 38(5): 499-501.

Leite M S S C P, Almeida, M J B M. 2001. Compreensão de termos científicos no discurso da ciência. Revista Brasileira de Ensino Física, 23(4): 458-470.

Lopes A R C. 1999. Pluralismo cultural em políticas de currículo nacional. In: Moreira, A. F. B. (Org.) Currículo: políticas e práticas, Campinas: Papirus, p. 59-80.

Marques J G W. 2002. O olhar (des)multiplicado: o papel do interdisciplinar e do qualitativo na pesquisa etnobiológica e etnoecológica. In: Amorozo M C, Ming L C, Silva S M P (Eds.). Métodos de coleta e análise de dados em etnobiologia, etnoecologia e disciplinas correlatas. Rio Claro: Sociedade Brasileira de Etnobiologia e Etnoecologia, p. 31-46.

Martins, H de S. 2004. Metodologia qualitativa de pesquisa, Educação e Pesquisa, 30(2): 289-300.

Mortimer, E F, Chagas, A N, Alvarenga, V T. 1998. Linguagem científica versus linguagem comum nas respostas escritas dos vestibulandos. Investigações em Ensino de Ciências, 3(1): 7-19.

Ochoa G, McDonald S, Monk N. 2016. Embedding Cultural Literacy in Higher Education: a new approach, Intercultural Education, 27 (6), 546-559.

Posey D A. 1997. Etnobiologia: teoria e prática. In: Ribeiro D (ed.). Suma Etnológica Brasileira, 1-15. Edição atualizada do Handbook of South American Indians. $3^{\text {a }}$ Edição, v. 1, Petrópolis: Vozes/FINEP.

Prado H M. 2012. O conhecimento de agricultores quilombolas sobre forrageio e uso de habitat por mamíferos de grande porte na Mata Atlântica: evidenciando a centralidade dos ambientes antropogênicos na constituição do etnoconhecimento (Vale do Ribeira, SP, Brasil). Tese de Doutorado, Instituto de Biociências, Universidade de São Paulo.

Toledo V. 1990. La perspectiva etnoecológica: cinco reflexiones acerca de las "ciencias campesinas" sobre la naturaleza con especial referencia a México. Ciencia, 4: 22-29. 